\title{
ОСОБЕННОСТИ ФОРМИРОВАНИЯ СТРАТЕГИЧЕСКОГО ПОРТФЕЛЯ ФАКТОРОВ ВНЕШНЕЙ СРЕДЫ СТРОИТЕЛЬНОЙ КОМПАНИИ
}

\author{
(c) 2020 Конников Евгений Александрович \\ кандидат экономических наук, доцент, Высшая инженерно-экономическая школа \\ Санкт-Петербургский политехнический университет Петра Великого, Россия, Санкт-Петербург \\ E-mail: konnikov.evgeniy@gmail.com
}

(C) 2020 Чорная Софья Александровна

Высшая инженерно-экономическая школа

Санкт-Петербургский политехнический университет Петра Великого, Россия, Санкт-Петербург

E-mail: sonya.chornaya@mail.ru

Строительная отрасль является одной из наиболее уникальных, с точки зрения экономического взаимодействия производителей и потребителей блага. Данный факт в первую очередь обусловлен уникальной ценностной спецификой объектов строительства. Данная специфика определяет значимость подготовительного этапа потребления, в первую очередь подразумевающего исследование рынка. Следовательно, эффективное многомерное представление строительной компании в информационной среде определяет результативность ее деятельности. Данное представление формируется под воздействием множества факторов, полностью или частично неуправляемых со стороны компании. В рамках данной статьи авторы предлагают модель внешней среды строительной компании и укрупненный алгоритм ее анализа.

Ключевые слова: строительная компания, информационная среда, тональность, внешняя среда.

Известно, что строительная отрасль,- один из «китов», на которых держится российская экономика. Благодаря модернизации подходов возведения объектов строительства, создаются все новые и новые условия для поступательного развития экономики страны в целом. По данным министерства экономического развития РФ, на начало 2019 года темп роста экономики ускорился до $2,3 \%$, что почти в 1,5 раза выше прошлогодних значений показателя (по данным Росстата, экономический рост на начало 2018 года составил 1,6\%). Согласно отчету минэкономразвития РФ, наиболее высокий вклад в увеличение ВВП внесли такие отрасли, как промышленность и строительство (их вклад в экономический рост составил 0,6 п.п. и 0,3 п.п. соответственно) [1].

Условия существования компании на рынке строительных услуг с каждым годом подвергаются всё большему давлению со стороны государства, тенденций потребительского спроса, конкурентов и многих других внешних факторов. Строительство, как и любая другая отрасль, отличается многообразием взаимосвязей, участниками которых являются как сами компании (и их собственники), так и их партнеры (поставщики товаров/услуг), а также государ- ственные органы. По данным Росстата, с 2000 по 2017 гг. общее количество действующих строительных организаций в России увеличилось, что отчетливо видно по графику, представленному на рисунке 1 [1].

Повышенное влияние изменений в строительном секторе на показатели состояния экономики страны в целом, обусловило тот факт, что деятельность, осуществляемая в рамках данной отрасли жестко регламентирована законодательством. Причем, контроль осуществляется не только за соблюдением прав предпринимателей и непосредственных покупателей жилья, но также и за соблюдением застройщиком норм технического и технологического характера.

Исследование, представленное в данной работе, сформировано идеей о создании некой модели функционирования компании на рынке строительства, раскрывающей взаимосвязь внутренних финансовых показателей компании и ряда внешних факторов. Далее в этом разделе будет проведено подробное рассмотрение, примечательных для формирования модели, внешних факторов, которые в последствии выступят экзогенными переменными в анализе.

Изучение и аккумуляция информации, полученной из ряда аналитических отчетов и статей, 


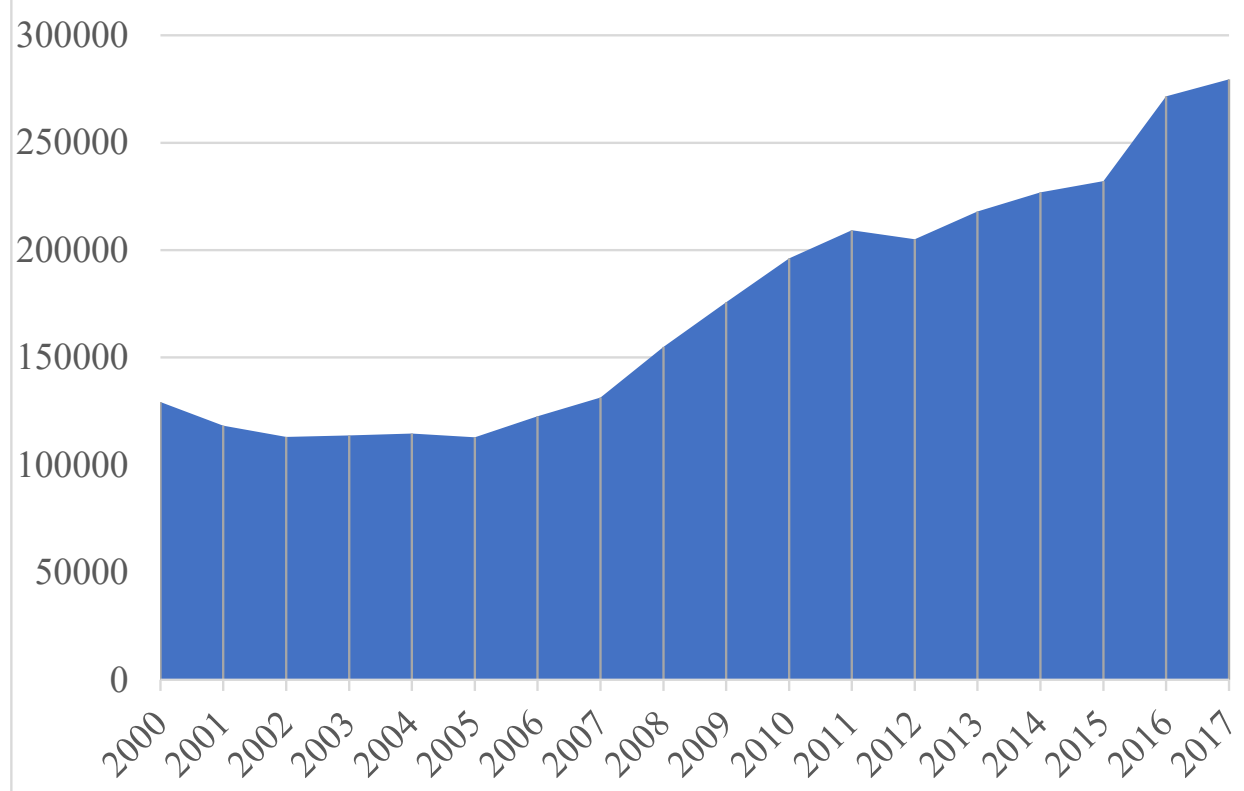

Рисунок 1. Число действующих строительных организаций в Российской Федерации

позволило сформировать пул факторов внешней среды, который в дальнейшем может быть применен при выборе направлений развития компании. Но, в большинстве проанализированных работ рассматривается влияние лишь объективных факторов, таких как, воздействие государства, динамики цен на естественные монополии, строительные материалы, а также цен реализации квадратного метра жилья и т.д., что отчасти, не позволяет провести углубленную оценку положения компании в отрасли.

Рассмотрим отношения компаниизастройщика с конечным потребителем в ключе модели В2C (Business to Client). Рейтинг застройщиков может формироваться не только по механизму ЕР3 (Единого реестра застройщиков). То есть путем автоматического расчета на основе накопленной в базе ЕРЗ информации о переносах даты ввода жилья, определяемой на основании опубликованных застройщиком проектных деклараций. Ранжирование может быть произведено так же с учетом информационного фона вокруг продукта компании, а также вокруг самого бренда застройщика. Данное информационное поле формируется в сети Интернет преимущественно за счет упоминаний компании в рейтинговых новостных источниках либо в группах в социальных сетях/на форумах, создаваемых непосредственно жильцами/дольщиками с целью обсуждения проблем, с которыми они сталкиваются. Например, качества постройки, наличие инфраструктуры, чистота отделки и другие. В связи с этим, было бы целесообразно сформировать некий набор показателей информационной среды, при помощи которых может быть произведено ранжирование компанийзастройщиков на рынке. Сразу отметим, что оценка влияния информационных факторов внешней среды может быть проведена при помощи программирования на Python.

Итак, одной из ключевых особенностей данного стратегического портфеля (пула) является то, что исследуемые факторы внешней среды по своей сущности представлены не только в виде ряда объективных факторов, но и также в виде метрик информационной среды. Впоследствии при выявлении точек стратегического роста и слабых мест в позиционировании застройщика на рынке, может быть проведена оценка взаимосвязи показателей внешней среды и финансового результата компании (ранее упомянутых, как показатели внутренней среды компании,т.е. эндогенные переменные в исследовании) с использованием упомянутого ранее пула факторов.

Проведем разбор, экзогенных относительно внутренней среды компании, факторов внешней среды. Структура факторов внешней среды отражена в таблице 1 .

Рассмотрим объективные факторы. Сектор «государство» включает пять факторов, формирование, поддержание и изменение которых в наибольшей степени происходит под влиянием аппарата государственной власти. 
Таблица 1. Пул факторов внешней среды строительной компании

\begin{tabular}{|c|c|c|}
\hline № & Сектор факторов & Фактор \\
\hline \multicolumn{3}{|r|}{ ОБЪЕКТИВНЫЕ } \\
\hline \multirow{5}{*}{1} & \multirow{5}{*}{ Государство } & $\begin{array}{l}\text { Корректировки в сфере налогообложения строительных органи- } \\
\text { заций. }\end{array}$ \\
\hline & & $\begin{array}{l}\text { Изменения в законодательных актах, оказывающих воздействие } \\
\text { на строительную отрасль }\end{array}$ \\
\hline & & Наличие государственных программ поддержки спроса на жилье \\
\hline & & Процент по ипотеке. \\
\hline & & Введение государственных проектов строительства \\
\hline 2 & Конкуренты & $\begin{array}{l}\text { Динамика цен реализации квадратного метра жилья аналогич- } \\
\text { ного класса }\end{array}$ \\
\hline \multirow{2}{*}{3} & \multirow{2}{*}{ Естественные монополии } & Динамика цен на электроэнергию \\
\hline & & Динамика цен на воду \\
\hline \multirow{2}{*}{4} & \multirow{2}{*}{ Поставщики } & Динамика цен на строительные материалы \\
\hline & & Динамика тарифов на услуги логистических компаний \\
\hline \multirow{4}{*}{5} & & ИНФОРМАЦИОННЫЕ \\
\hline & \multirow{3}{*}{ Потребители } & $\begin{array}{l}\text { Количество поисковых запросов наименования бренда застрой- } \\
\text { щика }\end{array}$ \\
\hline & & $\begin{array}{l}\text { Количество поисковых запросов типа «купить квартиру» + «наи- } \\
\text { менование бренда» }\end{array}$ \\
\hline & & Количество поисковых запросов «новостройки СПб» \\
\hline \multirow{3}{*}{6} & \multirow{3}{*}{ Новости } & $\begin{array}{l}\text { Динамика тональности новостей, в которых упоминается ком- } \\
\text { пания (негативность/позитивность-нейтральность новостного } \\
\text { фона) }\end{array}$ \\
\hline & & Количество упоминаний бренда компании в новостях \\
\hline & & Общий показатель тональности информационной среды \\
\hline
\end{tabular}

Налогообложение в России имеет свои особенности. При помощи налогов государство способно оказывать давление на функционирование предприятий, сдерживать и, наоборот, давать свободу стремительному развитию той или иной отрасли. Каждая компания в стране ежегодно направляет долю доходов «в казну». Существует ряд налоговых выплат, обязательных для каждой организации в стране (за исключением случаев с упрощенной системой налогообложения и компаний, попадающих под ЕНВД)

Помимо основных налогов таких как НДС, Налог на прибыль и на имущество, для строительных компаний характерны следующие налоговые выплаты:

- Налог на пользователей автомобильных дорог:

- Налог на содержание милиции и благоустройство территории

- Налог на содержание жилищного фонда и объектов социально-культурной сферы

- Транспортный налог 1\% (на содержание транспорта)
- Налог на транспортные средства (в т.ч. на только что приобретённые)

В дальнейшем одним из экзогенных факторов, относительно финансового результата компании, может рассматриваться налоговая политика государства в отношении строительной отрасли. Данные могут анализироваться путем сопоставления динамики изменения ряда финансовых показателей (Выручки, Чистой прибыли, Прибыли до налогообложения и суммы налоговый отчислений) с изменениями процентных ставок или введением/отменой налоговых льгот и иными корректировками в налоговом законодательстве за рассматриваемый период.

Наиболее важным и обсуждаемым событием в строительной отрасли стала реализация Федерального закона РФ от 30 апреля 2004 г. № 214-Ф3 «Об участии в долевом строительстве многоквартирных домов и иных объектов недвижимости и о внесении изменений в некоторые законодательные акты РФ».

Введение данного нормативно-правового акта позволило установить больший контроль 
над деятельностью компаний-застройщиков, а также обеспечить соблюдение прав дольщиков. Так, в результате последних изменений данного Ф3 компании-застройщики:

- обязаны размещать всю имеющуюся по строящемуся объекту проектную декларацию в сети интернет;

- формируют стоимость выставляемого на продажу объекта недвижимости как произведения стоимости квадратного метра жилья на площадь приобретенного жилого помещения. (Что позволило обезопасить дольщиков от мошенничеств со стороны застройщика, связанных с несоответствием цены и оплаченных квадратных метров)

- несут финансовую ответственность за отказ устранить существенные дефекты в переданной квартире;

- участвовать в формировании компенсационного фонда (по 1\% от цены возводимого дома). (Что также является своего рода страхованием дольщиков от потери вложенных в жилье средств) [2].

Ключевым и наиболее обсуждаемым аспектом всех изменений в законодательстве является введение в пользование механизма эскроу-счетов в банках. С одной стороны, данное нововведение выступает в роли гаранта того, что дольщик получит жилье в срок, в надлежащем качестве и не потеряет вложенные средства. С другой стороны, использование эскроу-счетов сильно ограничивает застройщика в средствах, которые могут быть направлены на строительство того или иного объекта, что вынуждает компанию обращаться за дополнительным заемным финансированием в банк. А данные обстоятельства в перспективе приводят к тому, что цены на возводимое жилье будут расти. Рост цен соответственно скажется в первую очередь на спросе на недвижимость в негативном ключе, в связи с тем, что с каждым годом платежеспособность россиян становится всё ниже (а в свете событий, связанных с COVID-19, существует вероятность того, что ситуация ухудшится). Во-вторых, как следствие падения спроса, вероятнее всего произойдет перестройка рынка застройщиков в целом. Можно предположить, что часть застройщиков не выдержат конкуренции и либо покинут рынок в результате банкротства, либо в ходе осуществления сделок слияния и поглощения, что соответственно, приведет к увеличению консолидации в отрасли. А подобные колебания вполне в перспективе могут стать причиной того, что на рынке жилой недвижимости (и не только) останутся около 10 компанийзастройщиков, что по своей сущности ведет к монополизации строительной отрасли.

Но с другой стороны, снижение уровня реальных располагаемых доходов населения способно стать предпосылкой для развития рынка ипотеки. Кроме того, в текущем, 2020 году ключевая ставка ЦБ достигла исторического минимума, что выступило своего рода механизмом «подогревания» спроса и цен на жилье. В результате снижения ставки процентные ставки по ипотечному кредитованию тоже снизятся. По данным «Дом.РФ» на 18 июня 2020 года, средневзвешенные ставки во входящих в топ-15 ипотечных банков по рыночным продуктам снизились до 8,5-8,7\%. По мнению редакции РБК «...смягчение кредитно-денежной политики означает повышение доступности ипотеки, что критически важно в условиях тяжелой ситуации с доходами граждан. С другой стороны, станут дешевле и кредиты для застройщиков, что поддержит девелоперскую активность». Данный факт позволяет предположить, что ввод эскроу-счетов не повлияет на уровень спроса на жилье [3].

Известно, что спрос на результат деятельности строительных организаций имеет специфический характер. В рамках данного исследования преимущественно подразумевается анализ спроса на жилищное строительство (жилые дома). Кто покупает жилые дома в России? Государство, физические лица (население) и организации. Наиболее динамичным является спрос среди населения, он подвержен влиянию большей совокупности факторов. Страна развивается, население растет, а с ним и необходимость в новых жилых комплексах. В глобальном варианте на желание и возможность простого населения приобретать квартиры (или частные дома) влияет его платежеспособность и тенденции в обществе (общественное мнение). В связи с этим в качестве факторов были определены: процент по ипотечному кредитованию, наличие государственных программ стимулирования спроса (льготное жилье и т.п.). Кроме того, в данном случае стоит иметь в виду такой фактор, как динамика цен реализации квадратного метра жилья аналогичного класса у конкурентов.

В конце 2019 года британская аудиторскоконсалтинговая компания Ernst \& Young (EY) представила результаты обзора рынка жилищ- 
ного строительства России за 2018 год. Интересно, что в исследовании сделан упор на такие факторы внешней среды, как изменение цен и затрат на строительство (в таблице 1, см. сектор «Поставщики» и «Конкуренты»), а также изменение цен на естественные монополии (см. таблицу 1 , сектор «Естественные монополии») [4].

Известно, что на результат деятельности любой компании, и, в особенности, строительной, влияет ценовая политика субъектов естественных монополий. Скорость и качество выполняемых строительных работ напрямую зависит от бесперебойности поставок разного рода коммунальных услуг. Под коммунальными услугами в данном случае понимаются: услуги по передаче электрической и (или) тепловой энергии, водоснабжение/водоотведение. Отметим, что данными видами услуг рынок естественных монополий не ограничивается. В связи с этим необходимо отметить, что на эффективность механизма организации строительных работ также оказывают влияние транспортные услуги. Следовательно, при дальнейшем проведении исследования влияния фактора «цен на естественные монополии» на финансовый результат деятельности строительной компании, могут быть учтены данные о тарификации услуг железнодорожных перевозок, аэропортов, услуг в портах и (или) транспортных терминалах. (в дополнение, имеет место фактор цен на топливо и, следовательно, нефть). Анализ данного рода факторов может быть проведён на основании представленной в публичном доступе статистической информации о тарифах на тот или иной вид услуги субъекта рынка естественных монополий.

Ценность и суть создания стратегии заключается в том, чтобы просчитать все возможные риски, с которыми может столкнуться компания в ходе осуществления своей деятельности, и в результате выбрать наиболее удачную комбинацию тактических действий, в результате которых возможно будет компенсировать большее количество рисков. Рынок недвижимости из года в год становится ключевым драйвером развития строительной отрасли. Существует мнение, что она одна из наиболее стабильных и мало подвержена воздействию каких-либо внешних факторов. С одной стороны, да, строить будут всегда: дороги, школы и прочую инфраструктуру. Но довольно сложно сказать так о жилищном строительстве. Безусловно, население нуждает- ся в этом, но вопрос в возможностях. Насколько население нашей страны способно приобрести квартиру в новостройке? Кроме того, особенность сферы строительства заключается в том, что она плохо коррелирует с тенденцией диджитализации всего окружающего пространства (дистанционное управление производством, перевод офисов в онлайн, и т.д.).

Но тем не менее, на данном этапе развития цифровых технологий, любая компания почти каждой отрасли подвержена влиянию информационной среды. Строительные компании не исключение. В связи с этим имеют место такие факторы, как «количество запросов» в поисковых системах Google, Яндекс и иных. Зачастую такие запросы вводятся целевой аудиторией компании. Прежде чем приобрести жилую недвижимость, человек, потенциальный потребитель, проводит поверхностный анализ рынка недвижимости, выставляемой на продажу. Анализ может осуществляться через ввод тех или иных запросов в поиске, а затем при помощи наиболее релевантных сайтов в выдаче осуществляется сбор информации о средней стоимости, площади, местоположении и, главное, оценка общественного мнения (комментариев) о том или ином жилье. Кроме того, в данном случае, мнение о жилье/новостройке в сознании потребителя эквивалентно мнению о компаниизастройщике. На основании этого можно провести оценку востребованности строительной компании на рынке жилой недвижимости. (см. таблицу 1, сектор «Потребители»). Данный фактор информационной среды хорошо дополняется оценкой тональности новостных статей, в которых как-либо фигурировало наименование бренда компании. (см. таблицу 1, блок «Новости»).

Анализ тональности текста - это класс методов контент-анализа в компьютерной лингвистике, предназначенный для автоматизированного определения в текстах эмоционально окрашенной лексики и эмоциональной оценки авторов (мнений) по отношению к объектам, речь о которых идёт в тексте. Тональность - это эмоциональное отношение автора высказывания к некоторому объекту (объекту реального мира, событию, процессу или их свойствам/атрибутам), выраженное в тексте. Эмоциональная составляющая, выраженная на уровне лексемы или коммуникативного фрагмента, называется лексической тональностью (или лексическим 
сентиментом). Тональность всего текста в целом можно определить как функцию (в простейшем случае сумму) лексических тональностей составляющих его единиц (предложений) и правил их сочетания. При провидении анализа новостного фона также может быть применена токенизация,- разбиение текста на составляющие, которые в последствии могут быть квантифицированы и подвержены более точному анализу [5].

Прежде чем стратегический консультант примет решение о выборе той или иной стратегии компании, он проводит подробный анализ рисков. На сегодняшний день существует целая масса методов проведения анализа среды компании. Например, для определения положения компании в отрасли среди конкурентов составляется карта стратегических групп конкурентов.
Помимо этого, наиболее известными и классическими методами анализа являются: SWOT, PEST(EL), модель М.Портера «5 конкурентных сил», матрица BCG и многие другие. Выбор того или иного метода для осуществления анализа зависит от объема данных и информации об анализируемых компании и отрасли.

В связи с этим, алгоритм любого исследования можно разделить на несколько этапов. Итак, этапы оценки информации дифференцируем следующим образом: поиск, сбор, агрегирование, фильтрация, квантификация, систематизация и непосредственно анализ полученных данных. Представим его в виде схемы (см. рисунок 2).

В чем отличие методов и инструментов исследования? Методы,- это то, с какой стороны

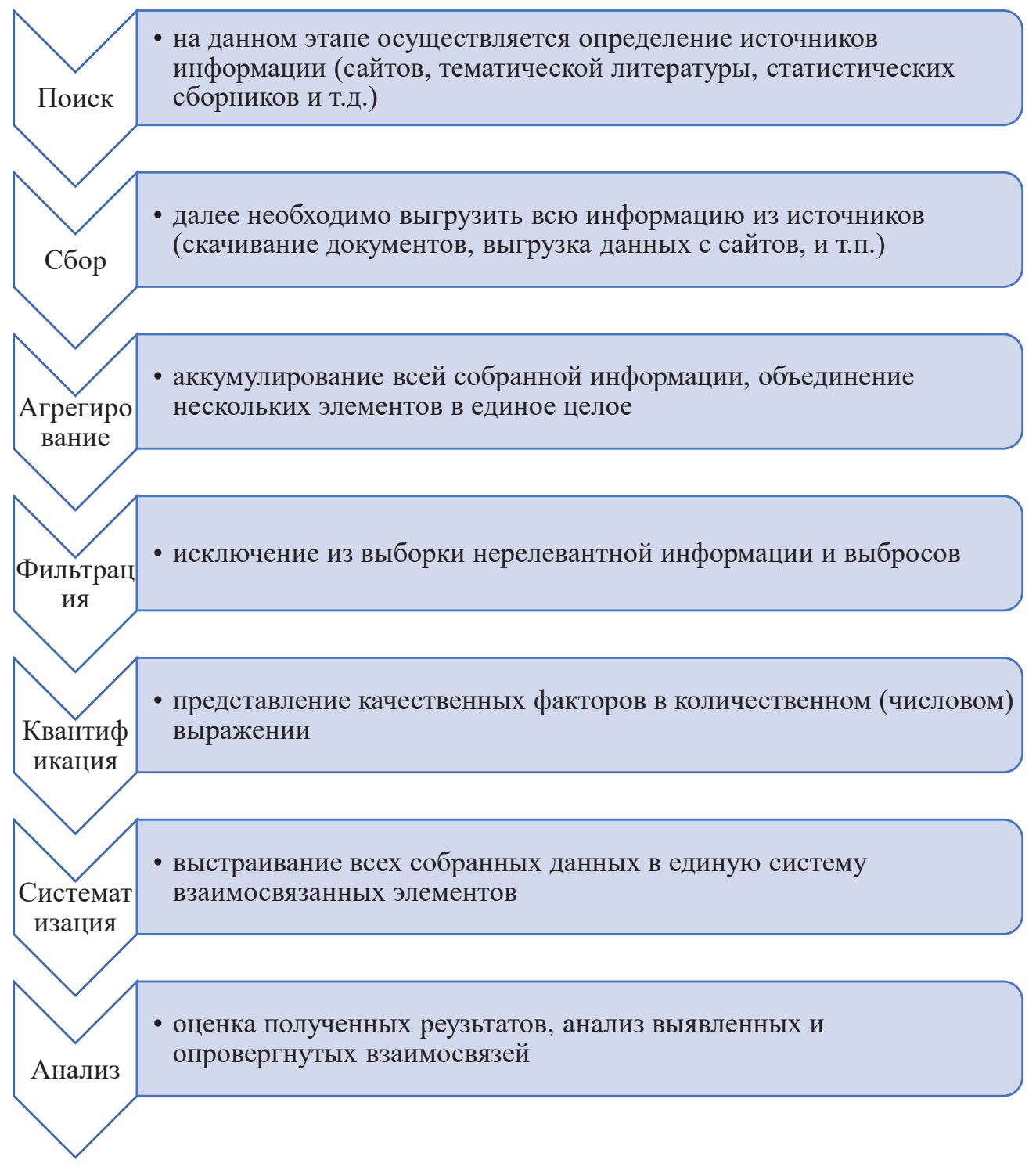

Рисунок 2. Алгоритм проведения исследования 
рассматривается вопрос. Инструменты,- то, санных ранее факторов внешней среды может при помощи чего реализуются те или иные ме- быть использован представленный ранее алготоды. Иначе говоря, пользуясь схемой на рисун- ритм проведения исследования. Он может быть ке 2 , можно сказать, что именно методы анализа реализован как вручную, так и с использовани(PESTEL, SWOT, стратегические матрицы и т.д.) ем Python-моделирования на каждом из этапов. начинают применяться лишь на заключитель- Заметим, что это актуально как для проведения ном этапе анализа. На всех предыдущих этапах оценки влияния объективных факторов, так и в работе участвуют лишь инструменты. информационных.

Итак, далее при проведении анализа опи-

\section{Библиографический список}

1. Федеральная служба государственной статистики http://old.gks.ru/wps/wcm/connect/rosstat_main/rosstat/ $\mathrm{ru} /$ statistics/enterprise/building/\#

2. Федеральный закон «Об участии в долевом строительстве многоквартирных домов и иных объектов недвижимости и о внесении изменений в некоторые законодательные акты Российской Федерации» от 30.12.2004 № 214-Ф3 (последняя редакция) [Электронный ресурс] - КонсультантПлюс - URL: http://www. consultant.ru/document/cons_doc_LAW_51038/ (дата обращения 26.11.2020).

3. Родионов Д.Г., Конников Е.А., Алферьев Д.А. Информационный капитал предприятия как целевой показатель развития в рамках цифровых экономических систем // Экономические науки. 2020. № 190. С. 131-137.

4. Родионов Д.Г., Ялымов С. В., Конников Е.А. Влияние информационной среды на субъекты малого и среднего предпринимательства // Экономические науки. 2020. № 189. С. 86-91.

5. Статья РБК «Ключевая ставка упала до исторического минимума. Что будет с ипотекой» от 19.06.2020 URL: https://realty.rbc.ru/news/5eec9f1e9a7947c3a97a9c5e

6. Ernst \& Young (EY) Обзор рынка жилищного строителства России, 2018 год - URL: https://assets.ey.com/ content/dam/ey-sites/ey-com/ru_ru/topics/real-estate-hospitality-and-construction/2019/ey-building-surveyrus-2019.pdf (дата обращения 28.11.2020).

7. Статья «Парсим на Python: Pyparsing для новичков» URL: https://habr.com/ru/post/239081/ 